\title{
Understanding the Learning Styles of Physiotherapy Students
}

\author{
Ruchi Desai ${ }^{1}$, Manali Shah ${ }^{2}$ \\ ${ }^{1,2}$ Assistant Professor, L J Institute of Physiotherapy, L J Campus, Ahmedabad \\ Corresponding Author: Ruchi Desai
}

\begin{abstract}
Physiotherapy students have wide range of diversity in their learning preferences therefore this has been always a challenged for the teachers to meet their demands. Understanding learning style preference encourages both students and teachers to continuously update themselves resulting in greater educational satisfaction.

Study was performed to find out differences of learning preferences from first to final year physiotherapy students of LJ Institute of physiotherapy, Ahmedabad, Gujarat. Total 220 physiotherapy students from all four years were invited to participate in study, out of which 161 students (male: 49, female: 112) voluntarily participated in study. A web-based survey was implemented in this study which included VARK questionnaire and we found $72.7 \%$ students have multimodal learning style and kinaesthetic was the preferred sensory modalities of learning for most of the years but final year also showed more aural learning. Most of the male students in our study showed kinaesthetic learning and previous year academic performance also has influence on learning preference.
\end{abstract}

Keywords: VARK, learning style, Physiotherapy

\section{INTRODUCTION}

The trends of education have changed from a teacher-centered to the student-centered learning in recent years. Therefore, it is essential to identify different learning styles and accordingly choose teaching styles for preferred learning ${ }^{(2)}$.

Physiotherapy students have wide range of diversity in their learning preferences therefore this has been always a challenged for the teachers to meet their demands. (1,17) Physiotherapy students of each year study through various instructional methods including lectures, dissection, Practical, tutorials, clinical practice etc. So, every year students have to learn in different way to gain knowledge and develop their professional skills. Evaluating students learning styles may help to develop, design, format, and deliver educational programs and resources that will motivate and stimulate students' acquisition, integration, and application of information and professional knowledge in an attempt to enhance the performance of students. ${ }^{(1,7,17)}$

A variety of learning style theories and frameworks has been developed. The Visual, Aural, read and Kinaesthetic (VARK) questionnaire was developed by Neil D. Fleming and Coleen E. Mills in 1992 at New Zealand, which is a short, simple questionnaire designed to help students learn more effectively and help teachers to developed teaching strategies necessary to reach all students. ${ }^{(7)}$

VARK instrument, classifies learning preferences into four modes based on sensory modalities such as Visual (V) seeing graphs, charts, flow diagrams, drawings, diagrams, pictures, coloured word accents, demonstrations etc.; Auditory (A) - 
discussing, speech; Reading $(\mathrm{R})$ - reading books, word lists, writings, handouts; and Kinaesthetic (K) - physical touch, manipulating objects or materials. Students will have their own individual learning style preferences ranging from single preference (unimodal) to multiple (multimodal) preferences.

Many authors have been investigated learning style preferences in medical, dental and physiotherapy students using VARK instrument. ${ }^{(1,2,3,4,9,10,12)}$ But as every year there are different learning challenges faced by students of physiotherapy, little is known about the learning style preferences used by physiotherapy student of different years. Therefore, our study aims at finding differences of learning preferences from first to final year physiotherapy students of L J Institute of physiotherapy, Ahmedabad Gujrat.

Need of study: In India undergraduate Physiotherapy curriculum consist of 4 years of learning which includes thorough knowledge of theory, practical, of different subjects as well as clinical practice differing every year. Therefore, different learning challenges are faced by physiotherapy students of each year. And as there are very less studies about it the need of study is to find out the learning style preferences used by physiotherapy student of different years.

\section{METHODOLOGY}

Study design: This was a questionnairebased survey study.

Study was performed at L J Institute of Physiotherapy, Ahmedabad, Gujarat. Total 220 physiotherapy students from all four years were invited to participate in study, out of which 161 students (male: 49, female: 112) voluntarily participated in study.

\section{Methods:}

Data were collected between January 2021 to March 2021. A web-based survey was implemented in this study. A selfadministered questionnaire for each year separately was used for data collections that questionnaire contained two parts (part A\&B). Part A consisted of demographic information (name, age, gender) and academic performance of last year university or board exam. and part B was the latest version of VARK questionnaire (version 8.01) from official VARK website (https://vark-learn.com/the-varkquestionnaire/) including self-administration of interpretation of VARK score.

A Pilot study was performed on randomly selected 5 students from each year. The purpose of the study was explained to the students and written inform consent was obtained before the administration of survey. VARK questionnaire was also explained to students, it consisted of 16 questions with 4 options each. And respondents could Choose more than one option if they found suitable. Each student was given 15-20 minutes to fill up questionnaire and at the end they had to self-administer obtained score from VARK.

Data Analysis: using SPSS version 20 the data was managed and analyzed. Continuous variables were expressed is mean and SD. Whereas categorical variables were express in form of frequency table and percentages. The histogram was also used to see the normality of quantitative data. The comparison of the preferences for the four VARK modalities of the male and female students was done using independent student $t$ test. A comparison of mean score of individual score of VARK components among students of each academic year and previous year academic year performance were done using ANOVA test. Level of significance was kept 0.05 .

\section{RESULT}

Out of 161 physiotherapy students 49 were male $(30.4 \%)$ and 112 were female $(69.6 \%)$. Number of students participated in our study from first year, second year, third year and final year are shown in chart no 1 . 


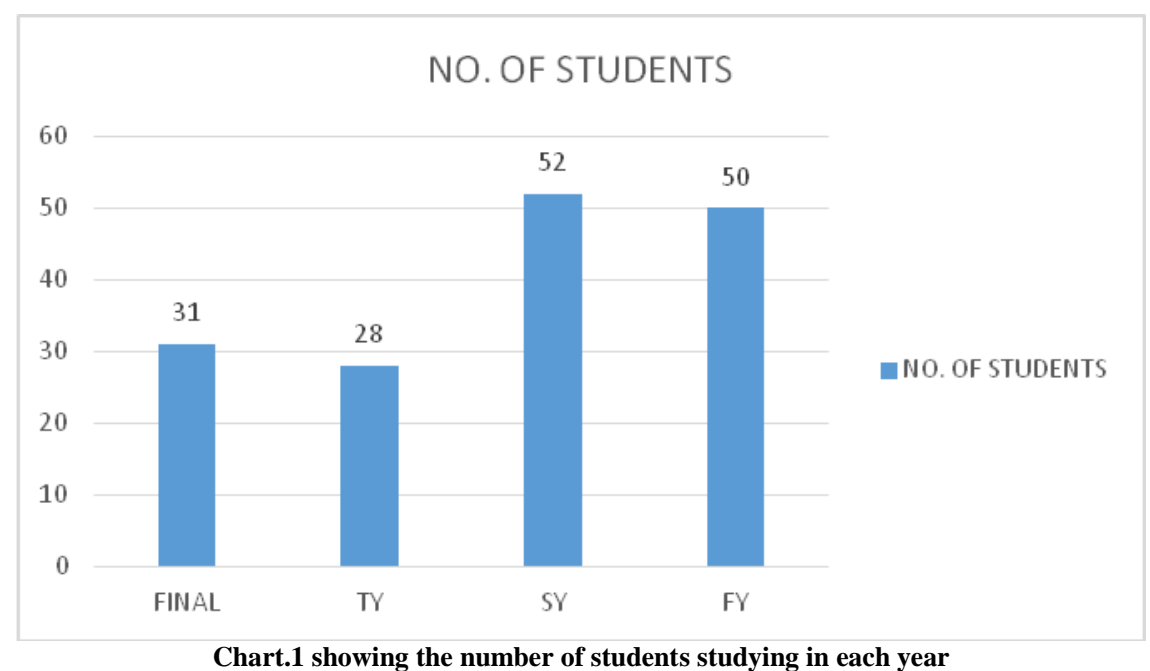

The academic performance of all Participants based on their previous year result are classified in to distinction $(\mathrm{n}=6)$, first $(n=97)$, second $(n=34)$ and pass $(n=24)$ gradings and shown in table no 1.

Table: 1 is showing grading of all Participants based on their previous year academic performance.

\begin{tabular}{|l|l|l|l|}
\hline Grading & No. Of Students & Percentage (\%) \\
\hline Distinction & $>75 \%$ & 6 & 3.7 \\
\hline First & $60-75 \%$ & 97 & 60.2 \\
\hline Second & $50-60 \%$ & 34 & 21.1 \\
\hline Pass & $<50 \%$ & 24 & 14.9 \\
\hline Total & & 161 & 100.0 \\
\hline
\end{tabular}

Table: 2 is showing learning preference style of participants

\begin{tabular}{|l|l|l|}
\hline Category & No Of Students & Percentage \\
\hline Multimodal & 117 & 72.7 \\
\hline Trimodal & 28 & 17.4 \\
\hline Bimodal & 9 & 5.6 \\
\hline Unimodal & 7 & 4.3 \\
\hline & 161 & 100.0 \\
\hline
\end{tabular}

learning style of preferance of students

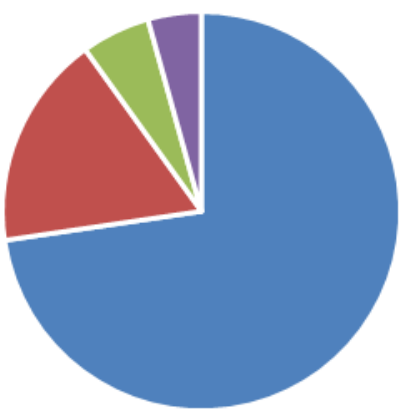

- MULTIMODAL - TRIMODAL = BIMODAL - UNIMODAL

Chart:2 is showing learning preference style of participants

According to VARK model in our study there are multimodal (72.7\%), trimodal (17.4\%), bimodal (5.6\%) and unimodal $(4.3 \%)$ learning preference style of participants. (Shown in table: 2 and chart: 2)

Mean VARK score for individual sensory modalities of learning are shown in table no 3. The mean score was highest for kinesthetic learning $(7.09 \pm 2.69)$ and lowest for read /write learning. $(6.15 \pm 2.56)$

Table: 3 Mean score of individual VARK components

\begin{tabular}{|l|l|l|}
\hline Category & Mean & SD \\
\hline visual & 6.65 & 2.84 \\
\hline aural & 6.80 & 2.98 \\
\hline read/write & 6.15 & 2.56 \\
\hline kinaesthetic & 7.09 & 2.69 \\
\hline
\end{tabular}

A comparison of mean score of individual score of VARK components among students of each academic year was done using ANOVA test at $\mathrm{p}<0.05$ and result suggested significant difference. (Shown in table: 4)

Table: 4 Mean Score of Individual VARK Components for Each Academic year.

\begin{tabular}{|l|l|l|l|l|}
\hline \multicolumn{5}{|l|}{ VARK Component } \\
\hline Year & V & A & R & K \\
\hline FY & $6.82 \pm 2.86$ & $7.12 \pm 3.24$ & $6.86 \pm 2.60$ & $7.42 \pm 2.76$ \\
\hline SY & $5.84 \pm 2.82$ & $5.73 \pm 2.82$ & $5.44 \pm 2.41$ & $6.34 \pm 2.54$ \\
\hline TY & $7.17 \pm 2.22$ & $7.25 \pm 2.36$ & $6.82 \pm 2.01$ & $7.28 \pm 2.99$ \\
\hline FINAL & $7.17 \pm 3.13$ & $7.65 \pm 2.89$ & $5.58 \pm 2.82$ & $7.65 \pm 2.34$ \\
\hline
\end{tabular}

A comparison of mean score of individual score of VARK components among students according to their grade was done using ANOVA test at $\mathrm{p}<0.05$ and result suggested significant difference. (Shown in table: 5) 
Table: 5 showing mean and SD of individual VARK components in students with distinction, first, second and pass grade.

\begin{tabular}{|l|l|l|l|l|}
\hline GRADE & $\mathbf{V}$ & $\mathbf{A}$ & $\mathbf{R}$ & $\mathbf{K}$ \\
\hline Distinction & $8.50 \pm 1.97$ & $9.33 \pm 1.03$ & $7.33 \pm 1.21$ & $8.83 \pm 3.13$ \\
\hline First & $6.61 \pm 2.80$ & $6.51 \pm 2.88$ & $5.98 \pm 2.52$ & $7.08 \pm 2.79$ \\
\hline Second & $6.50 \pm 3.22$ & $6.85 \pm 3.24$ & $5.97 \pm 2.50$ & $6.65 \pm 2.31$ \\
\hline Pass & $6.54 \pm 2.60$ & $7.25 \pm 3.07$ & $6.79 \pm 2.99$ & $7.33 \pm 2.63$ \\
\hline
\end{tabular}

Table 6 shows the comparison of the preferences for the four VARK modalities of the male and female students. It was observed that there was a significant difference among male and female students on kinesthetic learning preference. Other mode does not show any significant difference among male and female students.

Table: 6 showing comparison of VARK scores of male and female students

\begin{tabular}{|l|l|l|l|}
\hline & Gender & Mean \pm SD & P Value \\
\hline \multirow{2}{*}{ V } & Male & $6.1 \pm 2.80$ & 0.11 \\
\cline { 2 - 3 } & Female & $6.88 \pm 2.83$ & \\
\hline \multirow{2}{*}{ R } & Male & $6.94 \pm 2.70$ & 0.67 \\
\cline { 2 - 3 } & Female & $6.73 \pm 3.09$ & \\
\hline \multirow{2}{*}{ K } & Male & $5.86 \pm 2.59$ & 0.34 \\
\cline { 2 - 3 } & Female & $6.27 \pm 2.55$ & \multirow{2}{*}{0.03} \\
\cline { 2 - 3 } & Male & $7.86 \pm 3.07$ & \\
\hline
\end{tabular}

\section{DISCUSSION}

Keefe defined Learning style as 'composite of characteristic cognitive, affective and physiological characters that serve as relatively stable indicators of how a learner perceives, interacts with and responds to the learning environment'. (5) According to Dunn et al. It is important to recognize two factors that influence learning; one is stimuli (environmental, emotional, sociological, physical and psychological) and another is preference for learning/ processing new information. (6) Differences between learning and teaching may lead to frustration in students. This can be reduced by knowing the students learning style preferences which can be employed to teach them. When teaching is done by knowing students preferred learning style, not only teachers are better able to connect with students but students also achieve higher scores.

To know learning style preferences there are various tools / questionnaire available, the present study administered the VARK questionnaire to the physiotherapy students of all years to determine their learning style preferences.

In our study majority of students had multiple learning preferences $(72.7 \%)$. similar results have been reported by authors from different geographic locations. ${ }^{(8,11,13)}$ The predominant sensory modality of learning by mean score of VARK components of all subjects was kinesthetics and followed by aural, visual and read/write respectively.

In physiotherapy colleges teaching is predominately consist of lectures classes using PowerPoint presentation, chalk board teaching, practical practice in small groups on models or patients etc. but these teaching methods are general for all type of learners in all year of physiotherapy students.

General teaching methods doesn't stimulate all type of learners, for example, visual learners only may understand with PowerPoint presentations but not kinesthetics type of learners. However multimode preference of learning may cope up of with general teaching method.

In our study there was a significant difference in an individual VARK score from first year to final year, so general teaching method should not be implemented from first year to final year students. For example, first year students may learn more from lectures and tutorials while as progression to final year students may require more of discussion, hands on practice, case studies and clinical exposure.

In our study gender and learning style was assessed and we found a significant difference between them. Some of the study shows there is a significant difference $^{(4,14)}$ and some had denied. In current study we found males are having more kinaesthetic learning Preference than female.

Unlike a previous study ${ }^{(3,11)}$ which showed no influence of academic 
performance on learning style preference, our study showed a significant difference that students with distinction preferred more for aural learning.

Thus, it is important to assess learning style of student according to academic year, gender and academic performance of students by teachers as well as students themselves to get self-awareness of how he or she learns best and also for teachers to seek out the best methods to improve learning performance ${ }^{(15,16)}$

\section{CONCLUSION}

Our study was an attempt to describe the learning styles of undergraduate physiotherapy students in our institute. Based on the questions raised by previous studies, we also studied the influence of gender, previous academic performance and year of study on learning style preference. Most of the students were multimodal learners, which is good from both a teaching as well as learning perspective. Kinaesthetic was the preferred sensory modality of learning for most of the years but final year also showed more aural learning. Most of the male students in our study showed kinaesthetic learning and previous year academic performance also have influence on learning preference. So, we should have an active effort to use a combination of teaching methods considering the different types of learners to make learning a more fruitful experience.

Limitation: our study was of short duration and comparison was among different year students studying in physiotherapy in future studies can be done to find out whether learning style changes of a student from first year to final year physiotherapy curriculum.

\section{ACKNOWLEDGEMENT}

The authors greatly appreciate the participation in this study of all physiotherapy students of L J Institute of physiotherapy Ahmedabad Gujarat.

\section{Conflict of Interest: None}

\section{Source of Funding: None}

\section{Ethical Approval: Approved}

\section{REFERENCES}

1. Dadia $S$, Gambhir $S$, Jeyanthi $S$ and Arumugam N. Learning Style Preferences Among Physiotherapy Undergraduate Students in Punjabi University, Patiala, Punjab. International Journal of Current Research. July, 2015; 7(07); 18545-18547.

2. Dissanayake TD. The Learning Styles and the Preferred Teaching Learning Strategies of First Year Physiotherapy Students. International Journal of Scientific and Research Publications, July 2014; 4 (7); 2250-3153

3. Urval RP, Kamath A, Ullal S, Shenoy AK, Shenoy N, Udupa LA. Assessment of learning styles of undergraduate medical students using the VARK questionnaire and the influence of sex and academic performance. Adv Physiol Educ. 2014 Sep;38(3):216-20.

doi: 10.1152/advan.00024.2014.

4. D Hess, BSc Physiotherapy; J M Frantz, $\mathrm{PhD}$. Understanding the learning styles of undergraduate physiotherapy students. AJHPE 2014;6(1):45-47. DOI:10.7196/AJHPE.226

5. Keefe, J.W. Learning style: Theory and practice. Reston, Virginia: National Association of Secondary Schools Principals .1987

6. Dunn, R. S and Dunn, K. Teaching secondary students through their individual learning styles.Practical approaches for grades 7- 12.Allyn and Bacon, Boston. MA 1993.

7. Fleming, N.D and Mills, C. Not another inventory, rather a catalyst for reflection. To Improve Academy 1992; 11:137- 55.

8. Prithishkumar IJ, Michael SA. Understanding your student: using the VARK model. J Postgrad Med. 2014 AprJun;60(2):183-6. doi: 10.4103/00223859.132337. PMID: 24823519.

9. Gayathri B, Indhu K. A study of learning style preferences among first year undergraduate medical students using VARK model. Education in Medicine Journal 2016. 8(4):15-21. DOI: 10.5959/eimj. v8i4.440 
10. Javadinia SA, Sharifzade G, Abedini M, Khalesi M, Erfanian M. Learning Styles of Medical Students in Birjand University of Medical Sciences According to VARK Model. Iranian Journal of Medical Education. 2012;11(6); 584-589.

11. Rai SS Khatri SM. Learning style among the outstanding physiotherapy undergraduate students. Pravara Med Rev 2014;6(4): 14-17

12. Peyman H, Sadeghifar J, Khajavikhan J, Yasemi M, Rasool M, Yaghoubi YM, Nahal MM, Karim H. Using VARK Approach for Assessing Preferred Learning Styles of First Year Medical Sciences Students: A Survey from Iran. J Clin Diagn Res. 2014 Aug;8(8): GC01-4. doi: 10.7860/JCDR/2014/8089.4667. Epub 2014 Aug 20. PMID: 25302208; PMCID: PMC4190729.

13. Muralidhara, D.V, Simbak, $\mathrm{N}$ and nor MNM. Learning style preferences of preclinical medical students in a Malaysian university, South-East Asian Journal of Medical Education; 2013 ;7(1):22-30
14. Philbin M, Meier E, Huffman S, Boverie P. A survey of gender and learning styles. Sex Roles 1995;32(7/8):485-494.

15. Merlot 2012. (Multimedia Educational Resource for Learning and Online Teaching): the active learning site with VARK learning styles inventory. At: www.merlot.org/merlot/viewCompositeRev iew.htm/id=14 5206.Accessed:January 30

16. Murphy, R.J, Gray, S.A, Straja, S.R and Bogert, M.C. 2004. Students' learning preferences and teaching implications. $\mathbf{J}$ Dent Educ;68(8):859-66

17. Hawk, T.F and Shah, A.J. Using learning style instruments to enhance student learning. Decis Sci J Innovat Educ. 2007; 5:1-19.

How to cite this article: Desai $\mathrm{R}$, Shah $\mathrm{M}$. Understanding the learning styles of physiotherapy students. Int $J$ Health Sci Res. 2021; 11(7):188-193. DOI: https://doi.org/10. 52403/ijhsr.20210727 